\title{
Autism Spectrum Disorder in Children with Functional Defecation Disorder
}

\author{
AHMED F. ABDALLAH, M.D.; NOHA T. EL-TANTAWI, M.D. and ASMA N. ABDULRAHMAN, M.Sc. \\ The Department of Pediatrics, Faculty of Medicine, Al-Mansoura University
}

\begin{abstract}
Background: Defecation-related functional gastrointestinal disorders are common problems in childhood. Children with neurodevelopmental disorder, including ASD, are regularly affected by gastrointestinal problems and dysbiosis of gut microbiota.

Aim of Work: To assess the prevalence of ASD symptoms in patients with FDD and to discover, its demographic and clinical predictors in those patients.

Patients and Methods: The study included 60 children with FDD diagnosed according to Rome IV criteria. ASD was diagnosed according to Childhood Autism Spectrum Test.

Results: The reported functional defecation disorders included functional constipation (FC) in 46 patients $(76.7 \%)$ and functional non-retentive fecal incontinence (FNRFI) in 14 patients (23.3\%). The prevalence of ASD in the FC patients was $(34.8 \%)$. Patients with ASD had significantly higher total criteria count when compared with patients without ASD. In addition, they had significantly younger age of onset and longer symptom duration. In patients with FNRFI, 3 patients $(21.4 \%)$ were diagnosed with ASD. Moreover, it was found that ASD patients had significantly younger age of onset and longer duration of symptoms.
\end{abstract}

Conclusions: The current study could identify ASD in 16 patients $(34.8 \%)$ with FC. In patients with FNRFI, 3 patients $(21.4 \%)$ were diagnosed with ASD.

Key Words: $A S D-F D D-F C-F N R F I$.

\section{Introduction}

FUNCTIONAL defecation disorders (FDD) are common problem in children. These include infant dyschezia, functional constipation and functional non-retentive fecal incontinence [1].

The pathophysiology of functional defecation disorders is probably multifactorial. Factors such as genetic predisposition, low socioeconomic status, and most frequently the development of withhold-

Correspondence to: Dr. Ahmed F. Abdallah, The Department of Pediatrics, Faculty of Medicine, Al-Mansoura University ing behavior after experiencing a painful or frightening evacuation have been proposed as factors leading to functional defecation disorders [2].

They are diagnosed according to Rome IV criteria. Symptoms varies from relatively mild, such as crying before passage of soft stools or infrequent defecation to severe problems with fecal impaction and the daily involuntary loss of feces in the underwear [3]

Children with FDD are exposed to a wide variety of behavioral and developmental disorders [4] In one study, it was found that a substantial number of children $(29 \%)$ presenting with a functional defecation disorder at a tertiary hospital has concomitant ASD symptoms raising attention that clinicians should be aware of ASD symptoms in children with functional defecation disorders [5].

The relation between FDD and ASD is though to be mediated through a reciprocal interaction involving gut microbiome. Two studies detected significant differences between children with ASD and healthy controls regarding gut bacterial composition [6,7].

In fact, a number of mechanisms underlying the interaction between gut microbiota, and ASD symptoms via the microbiota-gut-brain axis have been proposed, including immune, hormonal, or neuronal pathways [8].

\section{Aim of work:}

The present study aims to assess the prevalence of ASD symptoms in patients with FDD and to discover, its demographic and clinical predictors in those patients.

\section{Patients and Methods}

The present study is a cross sectional study. It was conducted at Mansoura University Hospital 
from March 2017 April 2018. All participants or their parents gave informed consent to participate in the study. The study included 60 children with FDD. They were selected according to the Rome IV criteria [9]. Patients were excluded if any of the following criteria was present: Other causes of chronic constipation e.g. chronic inflammatory bowel disease, celiac disease, history of large bowel surgery, congenital anorectal malformations, neurologic disease (complete spinal cord transection, multiple sclerosis, or spina bifida), genetic syndromes and known intellectual disability and/or an intelligence quotient of $<70$.

All patients included in the study were subjected to careful history taking, thorough clinical examination and Childhood Autism Spectrum Test (CAST).

\section{Statistical analysis:}

The collected data were coded, processed and analyzed using SPSS program (version 16) for windows. Continuous data were expressed in the form of mean $\pm \mathrm{SD}$ while categorical data were expressed in the form of count and percent. Comparison of continuous data were performed utilizing student $t$-test, while categorical data were done using Chi-square test. $p$-value less than 0.05 (5\%) was considered significant.

\section{Results}

The present study comprised 43 males $(71.7 \%)$ and 17 females $(28.3 \%)$ with an age of $7.5 \pm 2.9$ years. Fathers of the studied children were educated in $56.7 \%$ and manual workers in $76.7 \%$ while only $46.7 \%$ of the studied mothers were educated and $83.3 \%$ were housewives. The reported functional defecation disorders included functional constipation (FC) in 46 patients (76.7\%) and functional non-retentive fecal incontinence (FNRFI) in 14 patients $(23.3 \%)$. Other clinical characteristics in FC patients. The reported age of onset was $4.4 \pm 1.1$ years and duration of symptoms was $3.3 \pm 2.3$ years. Bleeding per rectum was reported in $15.2 \%$ of patients and $8.7 \%$ of patients had affected siblings. ASD was diagnosed in 16 patients (34.8\%).

Comparison between FC patients with ASD and patients without regarding the demographic data showed that patients with ASD had significantly lower rate of educated fathers when compared with patients without ASD. In addition, it was found that ASD patients had significantly younger age of onset and longer symptom duration. Moreover, it was found that patients with ASD had significantly higher total criteria count when compared with patients without ASD.

In FNRFI patients, the age of onset was $4.6 \pm 1.8$ and duration of symptoms was $2.9 \pm 1.6$ years. In only 1 patient $(7.1 \%)$ one sibling was affected. Three patients were diagnosed with ASD (21.4\%). No statistically significant differences were found between FNRFI patients with ASD and without regarding the demographic data. However, it was found that it was found that ASD patients had significantly younger age of onset and longer duration of symptoms.

\section{Discussion}

Atypical defecation habits are common and distressing for children and families and can have a major impact on quality of life. Often, no underlying factor can be identified, and the defecation disorder is considered functional [10] .

Defecation-related functional gastrointestinal disorders, such as infant dyschezia, functional constipation and functional non-retentive faecal incontinence, as defined and diagnosied by the Rome IV criteria, are common problems in childhood [11]

Searching for risk factors for these disorders, several studies have suggested an association between functional defecation disorders and overweight/obesity in children [12]. It was also found that the prevalence of stressful life events, including (sexual) abuse is significantly higher in children with functional defecation disorders compared with healthy children [13]. Moreover, the study of Kuizenga-Wessel et al., [14]. Found that $10.3 \%$ of children with FDDs had ADHD and $22.7 \%$ of children with a known diagnosis of ADHD fulfilled the Rome III criteria for an FDD.

Autism spectrum disorder (ASD) is a severely neuro-developmental disorder that impairs a child's ability to communicate and interact with others. Children with neurodevelopmental disorder, including ASD, are regularly affected by gastrointestinal problems and dysbiosis of gut microbiota [15]. Many studied linked ASD to FDD [16,17].

The present study aimed to assess the prevalence of ASD symptoms in patients with FDD and to discover, its demographic and clinical predictors in those patients. The study included 60 children with FDD diagnosed according to Rome IV criteria.

In the present study, the reported functional defecation disorders included functional constipation (FC) in 46 patients (76.7\%) and functional 
non-retentive fecal incontinence (FNRFI) in 14 patients $(23.3 \%)$.

Similarly, functional constipation was the most commonly reported functional gastrointestinal disorder in the study of Zhou et al., [18] accounting for $24.9 \%$ in 3671 students in Shanghai, China. Moreover, in the study of Burgers et al., [19] the authors evaluated the prevalence of pediatric functional defecation disorders (FDD) using the Rome III criteria and to compare these data with those obtained using Rome II criteria. They found that according to the Rome III criteria, $87 \%$ had functional constipation (FC) compared with only $34 \%$ fulfilling criteria for either FC or functional fecal retention based on the Rome II definition while 24 patients (11\%) fulfilled the criteria for FNRFI according to both the Rome II and Rome III criteria.

In another set of patients, Burgers et al., [20] using Rome III criteria recognized FC and FNRFI in $47 \%$ and $11 \%$ respectively in children patients with lower urinary tract symptoms. Likewise, in the study of Liem et al., [21] on 19 children with defecation disorders, 1 child $(5.2 \%)$ had functional non-retentive fecal incontinence and 16 children $(84.2 \%)$ had functional constipation. Also, in the study of Zablah et al., [7] on school-aged Salvadoran children using Rome III criteria, functional constipation was the most commonly diagnosed disorder in the studied children with a prevalence of $10.0 \%$.

Furthermore, in the recent study of KuizengaWessel et al., [17] on 282 children with FDDs, FC without FI was diagnosed in 175 children (62.1\%) while FC with FI was diagnosed in 82 children and FNRFI was diagnosed in 25 children (8.9\%). Most recently, Robin et al., [18] utilizing Rome IV criteria also noticed that functional constipation was the most common functional GI disorder in children and adolescents.

The current study used the recently introduced Rome IV criteria to diagnose the functional constipation disorders. Use of these criteria resulted in better identification and classification of these disorders in children $[\mathbf{9 , 1 0}$. The most commonly reported symptoms in FC patients in our study included few defecations and painful defecations. These data are in accordance with the study of Fathy et al., [5] who studied FC in a series of Egyptian children and reported few defecation motions and painful motions in $90.0 \%$ and $70.0 \%$ respectively in the studied children.

Regarding the prevalence of ASD in the studied FC patients, the current study could identify ASD in 16 patients $(34.8 \%)$. These findings are close to that found by the study of Peeters et al., [4] who prospectively assessed the prevalence of autism spectrum disorder (ASD) symptoms in children presenting with functional defecation disorders including FC and FNRFI. The study found that 61 patients out of $221(27.6 \%)$ with FC had ASD.

However, in the study of Pang and Croaker [14] on 118 children presented to a Pediatric Surgical Constipation results showed that 90 patients were otherwise normal; 18 patients had neurodevelopmental psychiatric diagnoses; 6 patients had ASD alone and 4 had ASD with other neurodevelopmental features revealing a notably lower prevalence of ASD than recognized by our study.

In the current study, comparison between FC patients with ASD and patients without regarding the reported Rome IV criteria showed that patients with ASD had significantly higher frequency of few defecations and fecal incontinence. In addition, it was found that patients with ASD had significantly higher total criteria count when compared with patients without ASD which is a novel finding reported by the present study.

This significant finding is supported by the study of Pang et al., [12] who studied constipation in children with ASD and found significantly higher frequency of incontinence that those without ASD.

Moreover, the present study found that patients with ASD had significantly younger age of onset and longer symptom duration. This is in accordance with the previous study of Peeters et al., [11]

In patients with FNRFI, 3 patients $(21.4 \%)$ were diagnosed with ASD. Moreover, it was found that ASD patients had significantly younger age of onset and longer duration of symptoms. These findings are lower than that reported by the study of Peeters et al., [11] who found that 9 out of 22 children (40.9\%) with FNRFI had ASD.

\section{Conclusions:}

The current study could identify ASD in 16 patients $(34.8 \%)$ with FC. Patients with ASD had significantly higher frequency of few defecations and fecal incontinence and higher total criteria count when compared with patients without ASD. Patients with ASD had significantly younger age of onset and longer symptom duration. In patients with FNRFI, 3 patients $(21.4 \%)$ were diagnosed with ASD. Moreover, it was found that ASD patients had significantly younger age of onset and longer duration of symptoms. 


\section{References}

1- BEAUDRY-BELLEFEUILLE I., BOOTH D. and LANE S.J.: Defecation-Specific Behavior in Children with Functional Defecation Issues: A Systematic Review. Perm J., 21, 2017.

2- BENNINGA M.A., TABBERS M.M. and VAN RIJN R.R.: How to use a plain abdominal radiograph in children with functional defecation disorders. Arch. Dis. Child Educ. Pract Ed. Aug., 101 (4): 187-93, 2016.

3- BERDING K. and DONOVAN S.M.: Microbiome and nutrition in autism spectrum disorder: Current knowledge and research needs. Nutr. Rev. Dec., 74 (12): 723-736, 2016.

4- BURGERS R., LEVIN A.D., Di LORENZO C., DIJKGRAAF M.G. and BENNINGA M.A.: Functional defecation disorders in children: comparing the Rome II with the Rome III criteria. J. Pediatr. Oct., 161 (4): 615-20.e1, 2012.

5- De ANGELIS M., PICCOLO M., VANNINI L., SIRAGUSA S., De GIACOMO A., SERRAZZANETTI D.I., et al.: Fecal microbiota and metabolome of children with autism and pervasive developmental disorder not otherwise specified. PLoS One, 8 (10): e76993, 2013.

6- FATHY A., MEGAHED A., BARAKAT T. and ABDALLA A.F.: Anorectal functional abnormalities in Egyptian children with chronic functional constipation. Arab. J. Gastroenterol. Mar., 14 (1): 6-9, 2013.

7- KANG D.W., PARK J.G., ILHAN Z.E.,WALLSTROM G., LABAER J., ADAMS J.B., et al.: Reduced incidence of Prevotella and other fermenters in intestinal microflora of autistic children. PLoS One, 8 (7): e68322, 2013.

8- KOPPEN I.J., KUIZENGA-WESSEL S., SAPS M., Di LORENZO C, BENNINGA MA, VAN ETTENJAMALUDIN F.S. and TABBERS M.M.: Functional Defecation Disorders and Excessive Body Weight: A Systematic Review. Pediatrics. Sep., 138 (3). pii: e20161417, 2016.

9- KOPPEN I.J., NURKO S., SAPS M., Di LORENZO C. and BENNINGA M.A.: The pediatric Rome IV criteria: What's new? Expert Rev Gastroenterol Hepatol. Mar., 11 (3): 193-201, 2017.

10- KOPPEN I.J., NURKO S., SAPS M., Di LORENZO C., BENNINGA M.A.: The pediatric Rome IV criteria: What's new? Expert Rev. Gastroenterol. Hepatol. Mar., 11 (3): 193-201, 2017.

11- KUIZENGA-WESSEL S., Di LORENZO C., NICHOLSON L.M., BUTTER E.M., RATLIFF-SCHAUB K.L., BENNINGA M.A. and WILLIAMS K.C.: Screening for autism identifies behavioral disorders in children functional defecation disorders. Eur. J. Pediatr. Oct., 175 (10): 13718, 2016.

12- KUIZENGA-WESSEL S., KOPPEN I.J.N., VRIESMAN M.H., Di LORENZO C., VAN DIJK M., BEELEN M.L.R., GROENEWEG M., STOFFELSEN R.J. and BENNINGA M.A.: Attention Deficit Hyperactivity Disorder and Functional Defecation Disorders in Children. J. Pediatr. Gastroenterol. Nutr. Jul 22, 2017.

13- LIEM O., BURGERS R.E., CONNOR F.L., BENNINGA M.A., MOUSA H.M. and Di LORENZO C.: Prolonged colonic manometry in children with defecatory disorders. J. Pediatr. Gastroenterol. Nutr. Dec., 59 (6): 748-53, 2014.

14-PANG K.H. and CROAKER G.D.: Constipation in children with autism and autistic spectrum disorder. Pediatr. Surg. Int. Apr., 27 (4): 353-8, 2011.

15- PEETERS B., NOENS I., PHILIPS E.M., KUPPENS S. and BENNINGA M.A.: Autism spectrum disorders in children with functional defecation disorders. J. Pediatr. Sep., 163 (3): 873-8, 2013.

16- PHILIPS E.M., PEETERS B., TEEUW A.H., LEENDERS A.G., BOLUYT N., BRILLESLIJPER-KATER S.N. and BENNINGA M.A.: Stressful Life Events in Children With Functional Defecation Disorders. J. Pediatr. Gastroenterol. Nutr. Oct., 61 (4): 384-92, 2015.

17- ROBIN S.G., KELLER C., ZWIENER R., HYMAN P.E., NURKO S., SAPS M., DI LORENZO C., SHULMAN R.J., HYAMS J.S., PALSSON O. and VAN TILBURG M.A.L.: Prevalence of Pediatric Functional Gastrointestinal Disorders Utilizing the Rome IV Criteria. J. Pediatr. Feb., 2. pii: S0022-3476 (17): 31634-7, 2018.

18- YANG Y., TIAN J. and YANG B.: Targeting gut microbiome: A novel and potential therapy for autism. Life Sci. Dec., 22. pii: S0024-3205 (17): 30665-3, 2017.

19- ZEEVENHOOVEN J., KOPPEN I.J. and BENNINGA M.A.: The New Rome IV Criteria for Functional Gastrointestinal Disorders in Infants and Toddlers. Pediatr. Gastroenterol. Hepatol. Nutr. Mar., 20 (1): 1-13, 2017.

20- ZHOU H., YAO M., CHENG G.Y., CHEN Y.P. and LI D.G.: Prevalence and associated factors of functional gastrointestinal disorders and bowel habits in Chinese adolescents: A school-based study. J. Pediatr. Gastroenterol. Nutr. Aug., 53 (2): 168-73, 2011.

21- ZHU J., GUO M., YANG T., LAI X., LEI Y.Y., HE M.L., CHEN J. and LI T.Y.: [Association between behavioral problems and gastrointestinal disorders among children with autism spectrum disorder]. Zhonghua Er Ke Za Zhi. Dec., 2; 55 (12): 905-910, 2017. 


\section{اضطراب طيف التوحد فى الأطفال الذين يعانون من اضطراب وظيفية التغور في التفار التين}

التغوط الاضطرابات المعدية المعوية الوظيفية ذات الهلة هى مشاكل شائعة فى مرحلة الطفولة. الأطفال الذين يعانون من اضطراب النماء

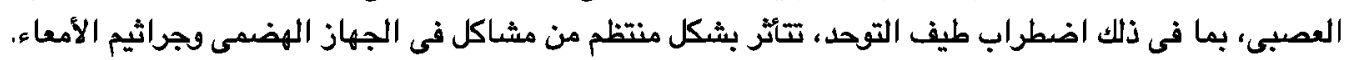

هدفت الدراسة الحالية إلى تقييم مدى انتشار أعراض اضطراب طيف التوحد فى المرضى الذين يعانون من اضطرابات التفوط الوظيفية،

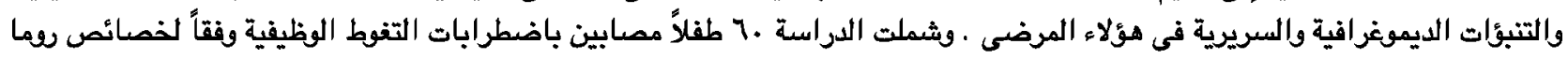

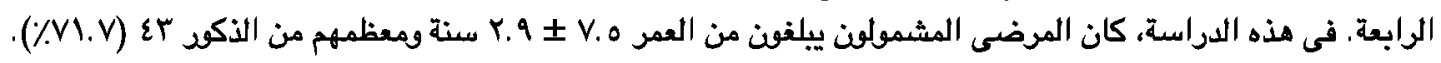

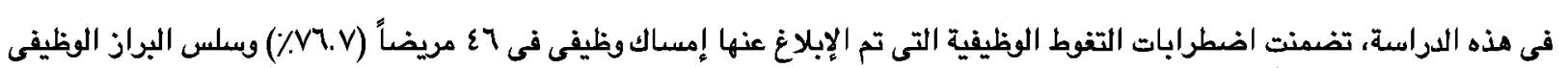

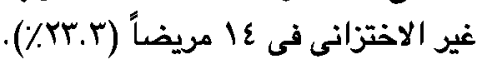

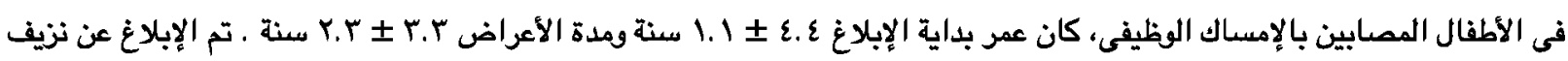

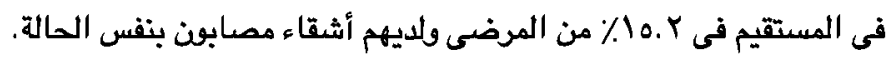

فيما يتعلق بانتشار اضطراب طيف التوحد فى المرضى الذين خضعوا للدراسة، يمكن اللدراسة الحالية تحديد اضطراب طيف التوحد فى

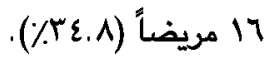

